\title{
Novel Approach for Forecasting and Assessing the Relationship Between the Environment Friendly Fibres Production Process and Fibres Properties
}

\author{
Basel Younes ${ }^{1,2}$ \\ ${ }^{1}$ Faculty of Engineering, University of Kalamoon, Damascus, Syria \\ ${ }^{2}$ Faculty of Mechanical and Electrical Engineering, Damascus University, Damascus, Syria \\ Email address: \\ basel.younes@uok.edu.sy, b.younes@damasuniversity.edu.sy, younesbasel@yahoo.co.uk
}

\section{To cite this article:}

Basel Younes. Novel Approach for Forecasting and Assessing the Relationship Between the Environment Friendly Fibres Production Process and Fibres Properties. American Journal of Science, Engineering and Technology. Vol. 5, No. 4, 2020, pp. 135-144.

doi: $10.11648 /$ j.ajset.20200504.13

Received: May 1, 2020; Accepted: June 4, 2020; Published: November 16, 2020

\begin{abstract}
This research will provide statistical forecasting models for the relationship between the production process and biodegradable aliphatic-aromatic co-polyester fibre properties. Spin draw ratio, birefringence, drawability, die head pressure, crystallographic order as full-width half-maximum, count, tensile properties, diameter, and thermal shrinkage was tested, analyzed and modeled using factorial experimental designs. Appropriate statistical methods were applied, and a model for specifying the direction of increasing or decreasing of the significant process parameters was identified. A statistical forecasting program was typically designed for optimizing fibers extrusion processes using Microsoft Visual Basic program, and then the predicted and calculated results were evaluated. The main goal of current research is to give basics for the novel optimization approach, and how these novel modeling methodologies will help polymer designers in making the best experimental decision, saving the power, the time and the cost. The statistical models and designed programs are important for controlling the production process to enhance fibre properties. The produced fibres could be used for different textile applications, as an alternative to commercial chemical fibres at reasonable cost.
\end{abstract}

Keywords: Environment Friendly, Bio-fibres, Melt-Spinning, Water Cooling, Statistical Analyzing, Forecasting

\section{Introduction}

Natural-based textiles are nearly $100 \%$ recyclable; recycling in biopolymer textiles allow environmental protection, energy and resource saving. However, biodegradable textiles do solve the problem. The biodegradable polymers and the technical progress in melt spinning processing technologies have achieved both qualitative and quantitative improvement in fibre manufacturing. Many scientists have worked to produce and develop new biodegradable polymers to be used in commercial products, such as textiles, ball-point pens, toothbrushes, bulk packaging, fishing lines, tennis racquet strings and wrapping paper... etc.

Environment friendly polymers are based on petroleum, agricultural or animal sources $[1,2]$, and offer a practical solution for the economy $[3,4]$, and used in many fields such as tissue culturing, biomedical, agriculture, food and textiles $[5,6]$.

The development of biodegradable aliphatic-aromatic copolyesters (AAC) started with different modes of degradation $[7,8]$. Several AACs have been developed during the last 20 years $[9,10]$, and a successful future is promised for the low product cost and the excellent properties $[11,12]$.

AACs have lower prices with economic benefits, widely available and lower priced monomers, such as butanediol, adipic acid and terephthalic acid. Aliphatic polyesters are biodegradable and sensitive to hydrolysis; their flexible chain fits into the active site of the enzyme [13]. Aromatic polyesters have an excellent pattern of physical properties, being strongly resistant to hydrolysis, bacterial and fungal attack [14], but they can be degraded when they are copolymerized with aliphatic polyesters [15]. When aromatic monomer groups are incorporated into the main chain of 
aliphatic polyesters, the mechanical properties are improved [16]. Researchers had established many standardized testing methods for evaluation the compostability and biodegradability of polymers using mixed cultures [17-22].

Aliphatic-aromatic co-polymers are used in biomedical [23, 24] and agricultural [25-28] applications by employing non-woven technology to produce products such as disposable wipes, refuse bags, seed mats and erosion control items [29, 30], green fibers have a shorter life cycle than those that are oil-based [31]. Aliphatic aromatic co-polyesters used in this research become commercialized [32, 33]. Inclusion and/or incorporation of aromatic monomer groups in the aliphatic polyesters' main chain can potentially enhance their mechanical properties [16]. Development of biodegradable aliphatic-aromatic co-polyesters began with the study of different modes of degradation [11, 12], and it had been characterized [34]. The randomness and the length of the polymer chains aid in understanding the biodegradation behavior for aliphatic-aromatic co-polyesters [35]. Environment friendly composites are process-able and had been used in non-woven, multi and monofilament yarn fabrics along with injection-molded products [36], production process parameters were controlled and analyzed [37].

Variation in bio-fibres spinning conditions leads to a better insight into the relationship between melt spinning process conditions and the fibre properties produced. Some researches based on statistical analysis, mathematical simulation and modeling of the processes of fiber formation had been done [38-47]. Different samples of as-spun linear aliphatic-aromatic co-polyesters were optimized and fibres properties were modelled [34].

The practical software-based approach improved the confidence benefits of experimental design and simulation $[48,49]$; it helps the engineering by reducing the target value variation in processes [50]. Furthermore, modeling of environment friendly composites' melt spinning process and factorial experimental design, optimization of the production processes for intelligent bio-fibers via statistical experimental design (SED) [51, 52], forecasting program for the fiber extrusion, as well as the future applications of biodegradable polymers in the modern textiles industry.

\section{Experimental}

\subsection{Materials}

Fully biodegradable, oil-based polymers were used in this research. A linear biodegradable oil-based polymer (1, 4benzenedicarboxylic acid, polymer with 1, 4-butanediol and hexanedioic acid, flexibility component of Solanyl Polymer supplied by the Rodenburg (the Netherlands)) and branched aliphatic-aromatic co-polyester (1, 4-butanediol, adipic acid, terephthalic acid, Ecoflex F BX 7011 (Germany)) were used. Linear polymer grade coded as LAAC and branched polymer grade coded as BAAC. Polymers' granules were dried at $65^{\circ} \mathrm{C}$ for 8 hours to avoid possible hydrolysis during the extrusion process according to the supplier data sheet.

\subsection{Fibre Extrusion Process}

The study describes the melt spinning of aromaticaliphatic co-polyester after modelling of the blend ratio effect on the mechanical properties of bio-fibres [53, 54], Experimental work was carried out in a single screw extruder (model 250, Figure 1) with a screw of diameter $25 \mathrm{~mm}$ and (L/D, length to diameter) ratio of 20: 1 from ESL Company, UK. The material was processed in the form of fibres. The fibres were water quenched with a bath temperature of $20 \pm 2^{\circ} \mathrm{C}$. The temperature profile was set after conducting a series of pre-experimental work using a statistical experimental design as a tool to optimise the process to give the best fibre properties. Polymer granules were fed through the hopper into the single screw extruder and then mechanically compressed and melted. The extrusion temperature profile controls the quality and the cost of manufactured fibers; the energy saving is achieved by balancing between the quality and the processing temperature profile using forecasting models.

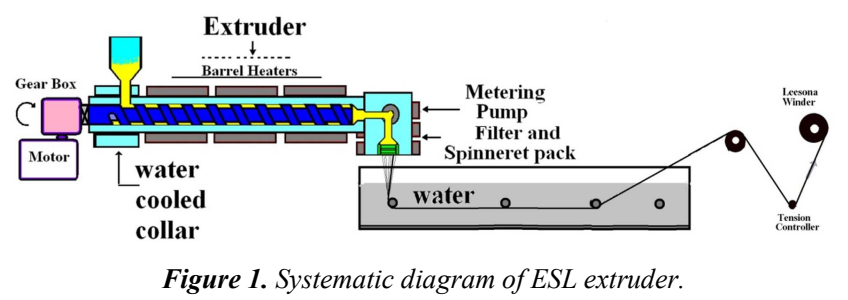

The screw conveys the molten polymer to the metering pump which feeds the spinneret at a constant rate. Upon exit from the die head, the fibres enter a water tank and were pulled by a take-up roller. The 30 hole spinneret (diameter is $0.4 \mathrm{~mm}, 1 / \mathrm{d}$ ratio is 1.2 ) was used. The main theme here is to lower the fibre tension affecting the fibre's structure and causing undesirable structural changes and to balance the factors' effects with regard to the material's rubbery behaviour. Alternatively, the high speed with wide range will omit the effect of other factors that need to be investigated. The low speed in such processes is compensated by use of a very large number of nozzles per spinneret; as a result, the comparable throughput can be obtained relative to the high speed process, such as upward and downward spinning processes. Because the glass transition temperature is notably below room temperature; AAC products will be soft and thermally unstable at standard processing temperatures.

\subsection{Mechanical Properties of As-spun Fibers}

Tensile testing of fibres was carried out using an Instron tester (model 3345) connected to Instron Bluehill V 2.21 software at a temperature of $20 \pm 2{ }^{\circ} \mathrm{C}$ and relative humidity $65 \pm 5 \%$. The initial gauge length was $50 \mathrm{~cm}$ stretched at a constant cross head speed $5000(\mathrm{~mm} / \mathrm{min})$, the instrument is working under test procedure ASTM D 1445. Pre-tension of 0.5 (cN/tex) was applied to the yarn to give a reproduce-able extension value; the samples were conditioned in the lab for 
48 hours before testing. Samples were taken from different parts of a package and the elongation at break was measured as a percentage of the original length.

\subsection{Thermal Shrinkage}

The thermal shrinkage test was carried out using the Testrite Thermal Shrinkage Oven, MK IV Shrinkage-Force from Testrite Ltd UK. The instrument comprises the heating chamber zone $(250 \times 110 \times 80 \mathrm{~mm})$, temperature controller, computer microprocessor, L. E. D readouts for results and the sliding carriage, plus a load cell and free shrinkage attachment. Using a load cell of $10 \mathrm{~g}$ and a shrinkage pot, samples were heated for 2 minutes at $60^{\circ} \mathrm{C}$. The thermal shrinkage is calculated as

$$
\text { Thermal shrinkage }(\%)=\left[\left(100 \times\left(L_{0}-L_{1}\right)\right) / L_{0}\right]
$$

Where:

$\mathrm{L}_{\mathrm{o}}$ is the original sample length and $\mathrm{L}_{1}$ is the shrinkage/ extension sample length under a constant tension.

\subsection{Modeling of Melt Spinning Process}

Modeling crosses the boundaries of academia, science and industry [55]. Measurement, feedback and adjustment, prediction and correction are the main elements in online quality control [56]. Figure 2 shows a flow chart for the methodology used for obtaining the program, starting from the data and statistical modeling methods and Statistical Experimental Design. Online quality control tools were utilized for prediction, measurement, correction as well as adjustment and feedback [56].

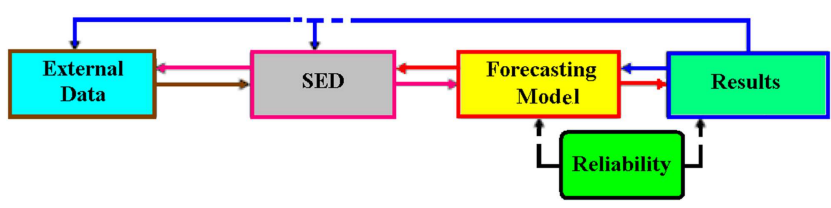

Figure 2. The flow chart of the statistical method.

Factorial experimental design provides data about the optimization of the average response values in regards to the factor levels [57]. The STATGRAPHICS program is used to design the experiment random order matrix and to simulate the main data in one block experiments [58]. The low melting point of these fibres improves high speed bonding in fabrication processes. Characterization and modelling include the production of semi-finished filaments, followed by more post-processes, in order to achieve a power-and materialsaving production plan and forecasting models for the novel friendly biodegradable fibres.

\subsection{Programming Using Microsoft Visual Basic}

Microsoft Visual Basic was used to write a forecasting program for the melt spinning process of as-spun aliphatic aromatic co-polyesters fibres. Visual Basic provides a high degree of simple automatic programming. The program offers the management of regression models of responses based on statistical factorial design, design analysis and process simulation. The simulation and the optimization of statistical database were achieved in many stages; it includes the design specification, definition, implementation and control.

The program was set at two interfaces: the first interface is the input window for process conditions; each factor is represented as a record and it may be owned by more than one record, leading to a network-like structure. The regression models obtained using statistical technique form the source code for the forecasting programme. The second interface is the output result window. The programmed application powerfully supports product development, design process control, quality assurance and product performance evaluation. All factors and dependencies between factors of the reality could be stored in the data model; it is structurally identified by their domains (names and kind of values). Each factor is represented as a record and relationships by a matrix design representing the relationship between factors. Results obtained should answer the fairly complex demands posed by multi-applications running concurrently with the application programs in the computer.

\section{Results and Discussion}

Factorial experimental design provides data about the optimization of the average response values in regards to the factor levels [57]. The STATGRAPHICS program was used to design the experiment random order matrix and to simulate the main data in one block experiments. Implementation of forecasting statistical methods plays a major role in creating a planning program and a plan for the production process regression.

Figure 3 shows an SEM photomicrograph of the crosssection and surface of the fibers; fibers had an acceptable uniform surface and possessed a uniform circular cross section. The studied factors for the fiber extrusion process include: air gap, metering pump speed, and winding speed, as well as, melt-spinning or extrusion temperature.

Table 1. Factors and the selected levels for the spinning experiments of as-spun fibers.

\begin{tabular}{lll}
\hline Factor abbreviation & Factor name & Low Level \\
\hline \multirow{2}{*}{ T } & Temperature of Melt-Spinning, ${ }^{\circ} \mathrm{C}$ (linear grade) & 130 \\
& Temperature of Melt-Spinning, ${ }^{\circ} \mathrm{C}$ (branched grade) & 145 \\
MPS & Metering Pump Speed, rpm $\left(2.4\right.$ cc.rev $\left.^{-1}\right)$ & 160 \\
AG & Air Gap between the die head and the water surface (cm) & 12 \\
WS & Winding Speed, m.min ${ }^{-1}$ & 4 \\
\hline
\end{tabular}




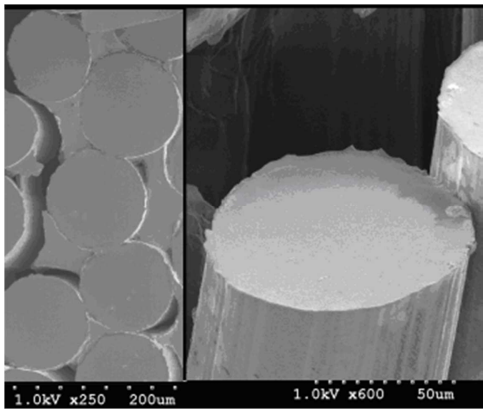

Figure 3. The surface and cross section of the biodegradable fibers.

The analyzed levels of each parameter were listed in Table 1 ; the sixteen trials matrix for the four control factors was applied for as-spun fibers analysis, Table 2.

A detailed experimental arrangement of the calculated results of spin draw ratio, birefringence, drawability, die head pressure, crystallographic order as full-width half-maximum (FWHM), count, tensile properties, diameter, and thermal shrinkage was completed (Table 3 and Table 4). Table 3 shows response data of fibre properties for the experiment of spinning of LAAC and Table 4 shows response data of fibre properties for the experiment of spinning of BAAC.

Table 2. L16 Experimental design array for the experiments (H=High, $L=$ Low).

\begin{tabular}{lllll}
\hline Trial Number & T & MPS & AG & WS \\
\hline 1 & H & H & H & L \\
2 & L & L & H & L \\
3 & H & H & H & H \\
4 & L & L & H & H \\
5 & L & H & L & L \\
6 & H & L & L & L \\
7 & H & L & H & L \\
8 & L & L & L & H \\
9 & H & H & L & H \\
10 & L & H & H & L \\
11 & H & L & H & H \\
12 & L & L & L & L \\
13 & L & H & H & H \\
14 & L & H & L & H \\
15 & H & H & L & L \\
16 & H & L & L & H \\
\hline
\end{tabular}

Table 3. Response data of fibre properties for the experiment of spinning of LAAC.

\begin{tabular}{|c|c|c|c|c|c|c|c|c|c|c|c|}
\hline $\begin{array}{l}\text { Trial } \\
\text { Number }\end{array}$ & $\begin{array}{l}\text { Spin Draw } \\
\text { Ratio }\end{array}$ & Biref $* 1000$ & $\begin{array}{l}\text { Drawa- } \\
\text { bility }\end{array}$ & $\begin{array}{l}\text { Die Head } \\
\text { Pressure (dpi) }\end{array}$ & FWHM $\left(^{\circ}\right)$ & $\begin{array}{l}\text { Count } \\
\text { denier }\end{array}$ & $\begin{array}{l}\text { Tenacity } \\
\text { g/den }\end{array}$ & E \% & $\begin{array}{l}\text { Modulus } \\
\text { g/den }\end{array}$ & $\begin{array}{l}\text { Diameter } \\
\mu \mathrm{m}\end{array}$ & $\begin{array}{l}\text { Thermal } \\
\text { shrinkage \% }\end{array}$ \\
\hline 1 & 12.9 & 10 & 5.4 & 979 & 0.622 & 2986.1 & 0.355 & 888 & 0.175 & 111.1 & -0.53 \\
\hline 2 & 21.3 & 48 & 3.1 & 1266 & 0.589 & 1821.2 & 0.299 & 582 & 0.159 & 87.0 & -0.24 \\
\hline 3 & 27.7 & 24 & 4.1 & 1066 & 0.644 & 1401.1 & 0.438 & 587 & 0.187 & 76.3 & -1.01 \\
\hline 4 & 41.6 & 37 & 2.9 & 1269 & 0.495 & 936.0 & 0.365 & 407 & 0.266 & 62.4 & -0.85 \\
\hline 5 & 12.8 & 12 & 5.6 & 1550 & 0.605 & 3038.4 & 0.329 & 873 & 0.190 & 112.2 & 0.17 \\
\hline 6 & 24.6 & 19 & 4.2 & 674 & 0.646 & 1581.8 & 0.388 & 743 & 0.176 & 81.0 & -1.02 \\
\hline 7 & 23.0 & 10 & 5.5 & 729 & 0.656 & 1686.6 & 0.428 & 679 & 0.183 & 83.6 & -0.76 \\
\hline 8 & 44.4 & 35 & 2.8 & 873 & 0.533 & 877.2 & 0.334 & 369 & 0.231 & 60.4 & 0.34 \\
\hline 9 & 26.7 & 31 & 4.2 & 1110 & 0.671 & 1448.6 & 0.428 & 707 & 0.204 & 77.5 & -1.29 \\
\hline 10 & 12.5 & 14 & 4.9 & 1453 & 0.643 & 3122.4 & 0.324 & 835 & 0.158 & 113.8 & -0.26 \\
\hline 11 & 44.1 & 45 & 2.7 & 679 & 0.643 & 882.4 & 0.662 & 377 & 0.237 & 60.5 & -1.60 \\
\hline 12 & 22.0 & 22 & 3.7 & 1168 & 0.594 & 1764.6 & 0.297 & 577 & 0.229 & 85.6 & 0.02 \\
\hline 13 & 22.8 & 27 & 3.9 & 1407 & 0.570 & 1707.6 & 0.314 & 538 & 0.216 & 84.3 & 0.02 \\
\hline 14 & 25.1 & 23 & 3.9 & 1069 & 0.645 & 1549.2 & 0.341 & 644 & 0.217 & 80.0 & -0.16 \\
\hline 16 & 48.0 & 47 & 2.8 & 720 & 0.541 & 809.8 & 0.635 & 401 & 0.225 & 57.8 & -2.22 \\
\hline
\end{tabular}

Table 4. Response data of fibre properties for the experiment of spinning of BAAC.

\begin{tabular}{|c|c|c|c|c|c|c|c|c|c|c|c|}
\hline $\begin{array}{l}\text { Trial } \\
\text { Number }\end{array}$ & $\begin{array}{l}\text { Spin Draw } \\
\text { Ratio }\end{array}$ & $\begin{array}{l}\text { Biref } \\
* 1000 \\
\end{array}$ & $\begin{array}{l}\text { Drawa- } \\
\text { bility }\end{array}$ & $\begin{array}{l}\text { Die Head } \\
\text { Pressure (dpi) }\end{array}$ & FWHM () & $\begin{array}{l}\text { Count } \\
\text { denier }\end{array}$ & $\begin{array}{l}\text { Tenacity } \\
\text { g/den }\end{array}$ & E \% & $\begin{array}{l}\text { Modulus } \\
\text { g/den }\end{array}$ & $\begin{array}{l}\text { Diameter } \\
\mu \mathrm{m}\end{array}$ & $\begin{array}{l}\text { Thermal } \\
\text { shrinkage \% }\end{array}$ \\
\hline 1 & 46.8 & 8 & 3.3 & 1275 & 0.610 & 937 & 1.2 & 118.2 & 1.4 & 58 & 3.88 \\
\hline 2 & 46.8 & 46 & 3.2 & 1275 & 0.574 & 937 & 1.1 & 97.9 & 1.2 & 60 & 3.88 \\
\hline 3 & 26.5 & 22 & 3.4 & 1632 & 0.635 & 1656 & 0.9 & 131.9 & 0.7 & 78 & 3.57 \\
\hline 4 & 31.4 & 35 & 3.3 & 1530 & 0.483 & 1394 & 0.8 & 118.4 & 0.9 & 72 & 3.45 \\
\hline 5 & 24.0 & 10 & 3.5 & 1530 & 0.596 & 1826 & 0.9 & 161.7 & 0.8 & 85 & 3.23 \\
\hline 6 & 13.3 & 17 & 3.5 & 1530 & 0.634 & 3303 & 0.7 & 148.6 & 0.5 & 110 & 2.91 \\
\hline 7 & 35.2 & 8 & 3.3 & 1530 & 0.648 & 1244 & 1.0 & 118.3 & 1.2 & 68 & 3.88 \\
\hline 8 & 34.7 & 33 & 3.3 & 1530 & 0.521 & 1263 & 1.1 & 126.5 & 1.1 & 69 & 3.64 \\
\hline 9 & 27.1 & 29 & 3.5 & 1632 & 0.658 & 1618 & 1.0 & 161.8 & 0.7 & 77 & 3.84 \\
\hline 10 & 24.5 & 12 & 3.5 & 1275 & 0.631 & 1788 & 0.9 & 153.7 & 0.6 & 81 & 3.40 \\
\hline 11 & 13.3 & 43 & 3.5 & 1938 & 0.633 & 3291 & 0.8 & 156.4 & 0.4 & 110 & 2.58 \\
\hline 12 & 13.4 & 20 & 3.5 & 1632 & 0.582 & 3280 & 0.7 & 161.5 & 0.5 & 112 & 2.75 \\
\hline 13 & 24.3 & 25 & 3.5 & 1530 & 0.559 & 1804 & 0.9 & 161.7 & 0.8 & 82 & 3.64 \\
\hline 14 & 13.3 & 21 & 3.5 & 1938 & 0.633 & 3294 & 0.6 & 160.5 & 0.4 & 111 & 2.02 \\
\hline 15 & 24.0 & 10 & 3.6 & 1275 & 0.635 & 1826 & 0.8 & 164.6 & 0.7 & 82 & 3.25 \\
\hline 16 & 26.6 & 45 & 3.6 & 1938 & 0.529 & 1647 & 0.9 & 167.4 & 0.8 & 79 & 3.23 \\
\hline
\end{tabular}


By investigating the relationship between the results, the matrix design presenting factors and their levels, it was found that the combination between the higher throughput flow rate and the high spinning temperature in the filaments' extrusion will lead to a decrease in the filament heating content and vice versa. For example; According to the drawability characterization, biodegradable fibers (i.e., as-spun) should consist of a drawn construction and be conducive to orient along the fiber axis of the chain [59].

There is a clear relationship between the spin (down) draw ratio and the orientation of the fibers and having a significant effect on the drawability. In other words, the overall orientation of fibers was increased and the draw ratio decreased as the spin draw ratio increased. The air gap between the die and water bath affects the properties of the polymer, it leads to increase in stress at break with increase in air gap and bath temperature while the elongation at break decreases for the same, and affects the way crystal grows in a polymer melt. Temperature significantly influenced the spin draw ratio and fibre drawability that affects the flow rate and tension value. To study the effects of the factors as well as their statistical significance an ANOVA study was conducted, the $\mathrm{P}$ value is determined using the graphic method $(\mathrm{P} \equiv \alpha$-significance level) and can be obtained from most modern statistical analysis programs. So, A factor was considered to have a significant effect if had P-value smaller than 0.05. The ANOVA results from the experiments are presented in Table 5. The significance of factors were $\mathrm{P}_{\mathrm{WS}}>\mathrm{P}_{\mathrm{MPS}}>\mathrm{P}_{\mathrm{T}}$ in the drawability analysis, while no significant effect was observed due to other factors. The P-value (0.036) of T\&WS is lower than 0.05 and therefore is significant. The most significant factors were T, MPS and WS. Metering pump speed was observed to have interaction with winding speed; the speeds' relationship oriented the fiber chains as well as added different spin draw ratio, having an effect on drawability later. Multiple and individual regressions optimized for the quality required for various applications and identified the factors' effects and interactions to determine the direction of those that are significant by using the estimated response surfaces. A twist was observed in the 3D surface response diagrams for $\mathrm{T}$ and WS (Table 5), thus the interaction is significant and agrees with the previous statistical results. This interaction will affect the structure of the as-spun fibers and help to extend the chains to achieve high orientation along the axis of fiber.

Table 5. ANOVA results (P-Value) of factor effects on the drawability.

\begin{tabular}{|c|c|c|}
\hline Source & $\mathbf{P}$ & $\begin{array}{l}\text { Estimated response surface for the } \\
\text { response (Example: drawability) }\end{array}$ \\
\hline T & 0.015 & $\begin{array}{c}\text { Estimated Response Surface } \\
M P S=10, A G=5.5\end{array}$ \\
\hline MPS & $\begin{array}{l}0.011 \\
0756\end{array}$ & Tha \\
\hline WS & 0.010 & $\begin{array}{r}3.6-4.4 \\
4.4-4.6\end{array}$ \\
\hline T \& MPS & 0.837 & $\begin{array}{r}4.6-4.9 \\
4.9 \cdot 5.8\end{array}$ \\
\hline $\mathrm{T} \& \mathrm{AG}$ & 0.776 & $780^{90^{100}}$ \\
\hline $\mathrm{T} \& \mathrm{WS}$ & 0.036 & 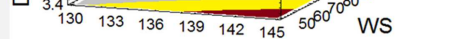 \\
\hline MPS\& AG & 0.189 & $\mathrm{~T}$ \\
\hline MPS \& WS & 0.338 & $(\mathrm{~T} \& \mathrm{WS})$ \\
\hline $\mathrm{AG} \& \mathrm{WS}$ & 0.987 & \\
\hline
\end{tabular}

Based on the analysis of the fraction factorial experimental design results and using STATGRAPHICS program, a simplified mathematical model was fitted. The forecasting model includes all interaction terms regardless of their significance. It is a sufficient basis for interpretation of the obtained relationships. The mathematical model was driven from the experimental data and the residual plot was analyzed to validate the regression formula.

The regression equation (1) was obtained from the analysis and forms the simplified models of the experimental data (coded values in Table 1). The regression equations forecast the fiber properties and accurately predict the properties in the final fibers produced. The mathematical regression model forms one of the basic source codes in the designed forecasting application, which will present the extrusion of bio- fiber.

Response $=\mathrm{a}+\mathrm{b} \times \mathrm{T}+\mathrm{c} \times \mathrm{MPS}-\mathrm{d} \times \mathrm{AG}+\mathrm{f} \times \mathrm{WS}+\mathrm{b}_{1} \times \mathrm{T} \times \mathrm{MPS}+\mathrm{b}_{2} \times \mathrm{T} \times \mathrm{AG}-\mathrm{b}_{3} \times \mathrm{T} \times \mathrm{WS}-\mathrm{b}_{4} \times \mathrm{MPS} \times \mathrm{AG}-\mathrm{b}_{5} \times \mathrm{MPS} \times \mathrm{WS}+\mathrm{b}_{6} \times \mathrm{AG} \times \mathrm{WS}$

Where: $a, b, c, d, e, f_{b 1-6}$, are statistical constants for the response calculated by the STATGRAPHICS program.

Employing the mentioned technique, the drawability, the overall orientation, spin draw ratio, crystallographic order, die head pressure, diameter, tensile properties, thermographic measurement and thermal shrinkage were also analyzed and modeled. The statistical analysis models simulated the significant factors, their interactions, and gave useful results with some expected outliers which could be due to experimental and/or testing errors.

\section{Forecasting Program for the Fiber Extrusion}

In the programming process, the relationship between the key inputs (Factors) and the performance measures (Responses) using factorial statistical experimental design technology were reported. Microsoft Visual Basic was used to write a forecasting program that could be utilized for the as-spun fibers' extrusion process. The program offers the management of regression models for responses based on statistical factorial design, design analysis and process simulation. Conversion and summarization of the $\mathrm{C}++$ source code into a simple flow chart was completed (Figure 4).

After selecting the polymer grade, the program requests the parameters' values, calculates the values' responses by using regression equations and then gives the results.

The data from the input conditions was used to obtain the structural, mechanical and physical data. The multiple regression analysis and previous forecasting models provide a basis for identifying the relationship between process-input 
and process-output data; and formation of a source code to be used in the forecasting program [41, 60]. Each factor is represented as a record and relationships between other factors through a matrix design. Results obtained should answer the fairly complex demands posed by multiapplications running concurrently with the application programs in the computer. It is limited by the regions of the studied factors between the factor levels.

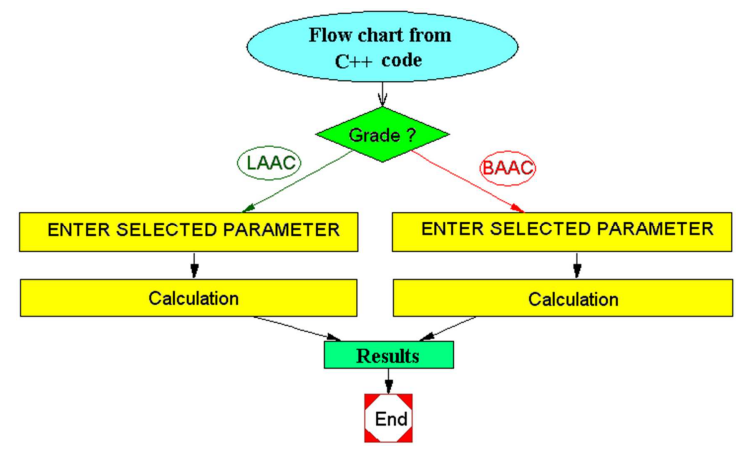

Figure 4. Schematic program process.

The program was designed as two windows. The first window is the input window for process conditions (Figure 5). Figure 6 shows the output interface/window for the fiber's structural, mechanical and physical properties. Each factor is represented as a record and it may be owned by more than one record, leading to a network-like structure. The modern optimization, experimental factorial design, and novel modeling methods help less experienced biopolymer designers; saving time, cost, and materials. Depending on the polymer's

nature and application, there are various methods in which biopolymers are processed, such as polymerization, crystallization and manufacturing. The material properties are highly dependent on the structure [61, 62]. For evaluation of the forecasting results obtained from melt spinning of as-spun fibres, selected conditions were processed as presented in Table 6 and Table 7, the estimates should be sufficiently accurate for practical application; the simulation results are in agreement with available data and within acceptable variation.

Table 6. Selected experimental conditions for linear grade.

\begin{tabular}{lllll}
\hline Trial No & T & MPS & AG & WS \\
\hline 1 & 130 & 6 & 3 & 50 \\
2 & 130 & 6 & 7 & 100 \\
3 & 130 & 7 & 4,5 & 100 \\
4 & 140 & 8 & 4 & 65 \\
5 & 135 & 8 & 4,5 & 85 \\
6 & 140 & 10 & 3,5 & 50 \\
7 & 140 & 10 & 4,5 & 85 \\
8 & 145 & 12 & 5 & 70 \\
\hline
\end{tabular}

Table 7. Selected experimental conditions for branched grade.

\begin{tabular}{lllll}
\hline Trial No & T & MPS & AG & WS \\
\hline 1 & 145 & 6 & 3 & 50 \\
2 & 150 & 6 & 7 & 100 \\
3 & 145 & 7 & 4,5 & 100 \\
4 & 150 & 8 & 4 & 65 \\
5 & 150 & 8 & 4,5 & 85 \\
6 & 155 & 10 & 3,5 & 50 \\
7 & 155 & 10 & 4,5 & 85 \\
8 & 160 & 12 & 5 & 70 \\
\hline
\end{tabular}

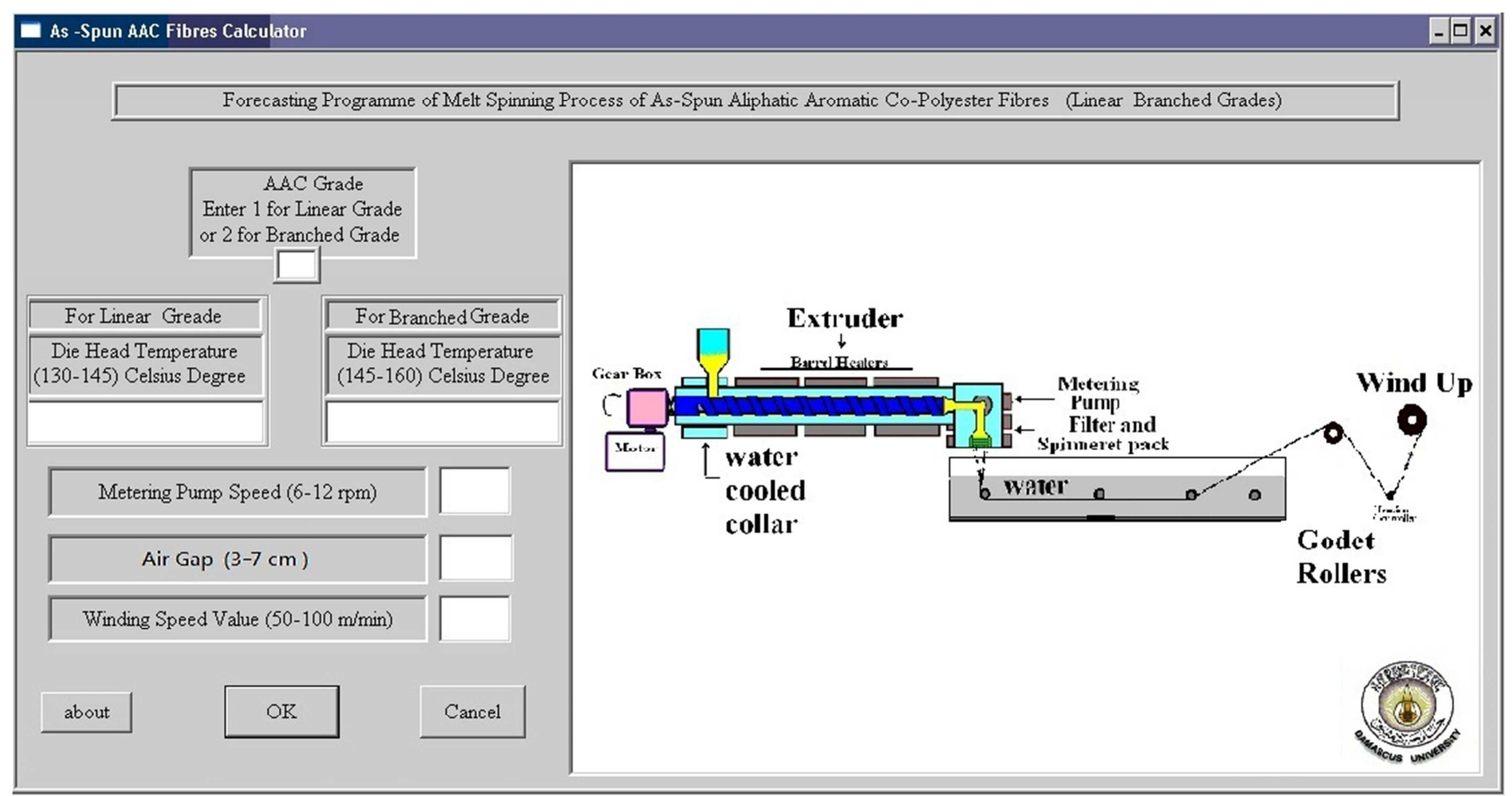

Figure 5. The main input interface/window for process conditions input. 


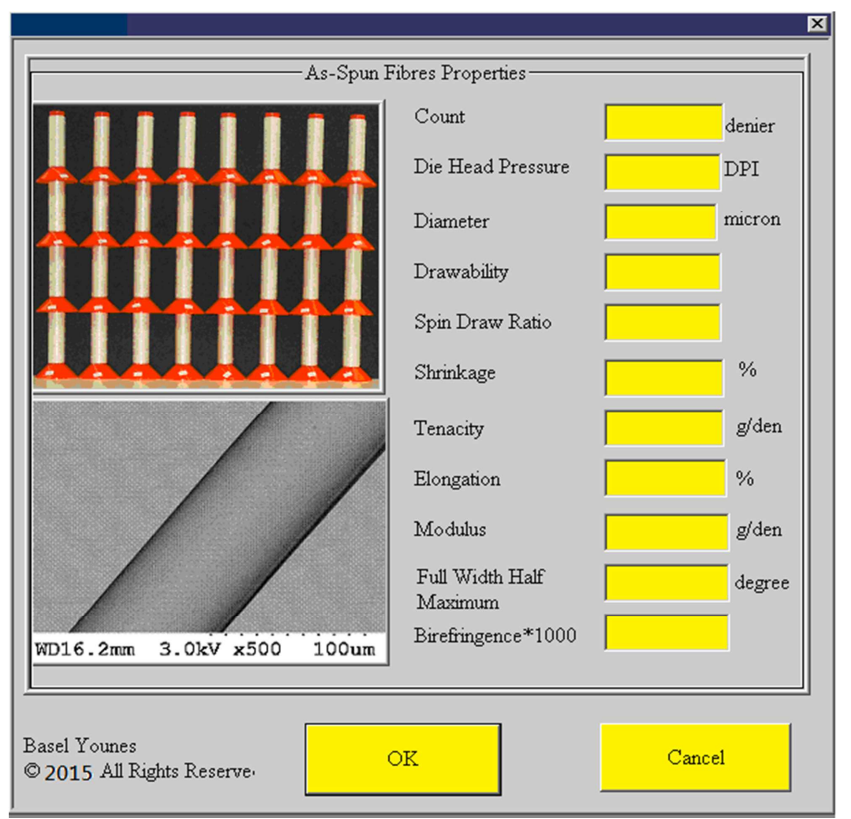

Figure 6. The output interface/window for filament properties.

In Figure 7 (As Example) the Drawability results were plotted with the predicted (Calculated) values on the $\mathrm{X}$-axis and the actual (Observed) values on the $\mathrm{Y}$-axis for all selected trials. The outputs were plotted versus the targets as red dots. A blue line indicates the linear fit. The fitted line plot command provides not only the scatter plot of the data adorned with the estimated regression function but also an estimated regression function. The most useful aspects of these plots are their ability to show nonlinear relationships between variables.

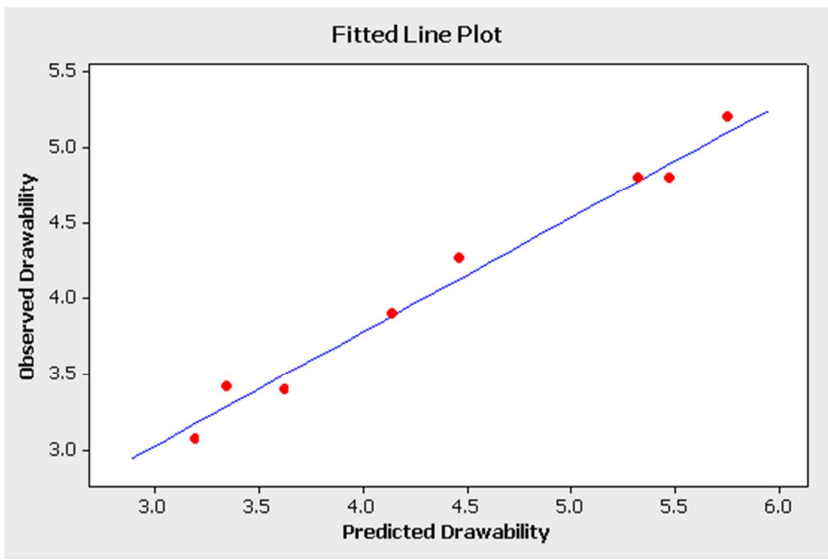

Figure 7. Fitted line plots between experimental observed drawability results and theoretical predicted results for drawability of bio- fibres (linear grade).

The experimental results for predicted and observed value of as-spun fibres properties had been listed in Table 8 and Table 9. The predictive models gave useful results for physical properties and notable variation for structural related properties as described previously, different samples of aliphaticaromatic co-polyester fibres were spun at different process profiles to determine the control parameters and their interaction effects and to test the forecasting regression equations. The importance of the achieved statistical models and designed programs lie in controlling the production process to optimize and enhance fibre properties which may improve the quality and give reasonable cost to biodegradable fibres. Due to their relationship with the internal structure of the fibres, the mechanical and thermal shrinkage properties of extruded fibres have a central role in the production processes.

Table 8. The experimental results for predicted and observed value of LAAC as-spun fibres properties (* P: Predicted and O: Observed).

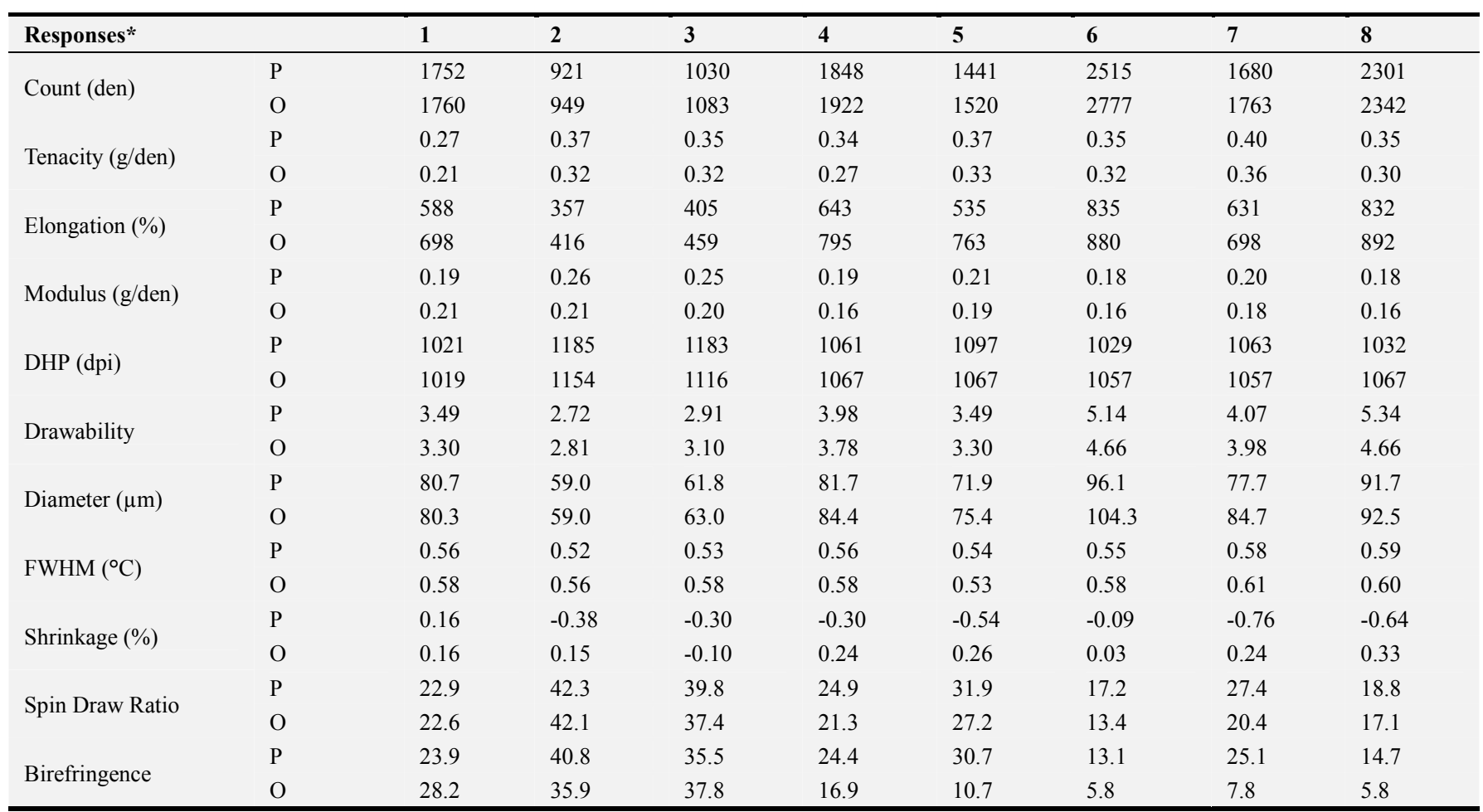


Table 9. The experimental results for predicted and observed value of BAAC as-spun fibres properties (* P: Predicted and O: Observed).

\begin{tabular}{|c|c|c|c|c|c|c|c|c|c|}
\hline Responses* & & 1 & 2 & 3 & 4 & 5 & 6 & 7 & 8 \\
\hline \multirow{2}{*}{ Count (den) } & $P$ & 1931 & 1329 & 1296 & 1906 & 1521 & 2608 & 1667 & 2429 \\
\hline & $\mathrm{O}$ & 1874 & 1085 & 1208 & 2026 & 1493 & 2855 & 1824 & 2424 \\
\hline Tenacity (g/den) & $\mathrm{P}$ & 0.75 & 0.84 & 0.87 & 0.81 & 0.87 & 0.73 & 0.87 & 0.75 \\
\hline \multirow{2}{*}{ Elongation (\%) } & $\mathrm{P}$ & 168 & 115 & 124 & 147 & 135 & 152 & 142 & 144 \\
\hline & $\mathrm{O}$ & 176 & 127 & 150 & 173 & 146 & 176 & 173 & 155 \\
\hline $\begin{array}{l}\text { Modulus } \\
\text { (g/den) }\end{array}$ & $\mathrm{P}$ & 0.63 & 0.99 & 0.93 & 0.66 & 0.79 & 0.29 & 0.66 & 0.48 \\
\hline \multirow{2}{*}{ DHP (dpi) } & $\mathrm{P}$ & 1456 & 1455 & 1520 & 1498 & 1498 & 1531 & 1531 & 1552 \\
\hline & $\mathrm{O}$ & 1387 & 1387 & 1474 & 1455 & 1436 & 1453 & 1455 & 1504 \\
\hline \multirow{2}{*}{ Diameter $(\mu \mathrm{m})$} & $\mathrm{P}$ & 82.8 & 69.1 & 68.9 & 81.7 & 73.6 & 96.3 & 77.3 & 93.3 \\
\hline & $\mathrm{O}$ & 82.5 & 66.0 & 63.7 & 86.1 & 74.0 & 105.4 & 82.5 & 94.3 \\
\hline \multirow{2}{*}{ Shrinkage (\%) } & $\mathrm{P}$ & 2.81 & 3.49 & 3.46 & 3.04 & 3.35 & 2.46 & 3.35 & 2.96 \\
\hline & $\mathrm{O}$ & 2.33 & 2.81 & 2.62 & 2.91 & 2.91 & 1.21 & 2.72 & 2.52 \\
\hline Spin Draw & $\mathrm{P}$ & 20.7 & 31.5 & 31.7 & 24.0 & 29.2 & 16.4 & 27.3 & 17.8 \\
\hline Ratio & $\mathrm{O}$ & 21.5 & 34.6 & 33.1 & 19.7 & 26.7 & 14.6 & 23.4 & 16.4 \\
\hline
\end{tabular}

Theoretically, the obtained statistical based models could be tested regarding the reported dynamic modelling of melt spinning process $[63,64]$ through a set of rate equations. Input and output values should be adjusted according to the material properties and the process conditions which aids in finding the general effect with some numerical differences in the results of the regression method obtained from such theoretical models.

In dry-laid or air-laid based non-woven technologies, short staple aliphatic-aromatic co-polyesters fibres could be used to produce various non-woven webs for medicine and agricultural applications. Post processes include the preparation of the fibres as new and smart friendly fibres to be weave-able, such as drawing, twisting, plying and the preparation processes for weaving. The main positive points regarding the production process could be summarised by the low processing temperature which assists in energy saving, low material and manufacturing costs, leading to lower product cost and the forecasting program which simulates the relationship between the responses and the setting of the production processes.

\section{Conclusion}

Environment friendly polymers used in the textile industry are an exciting area of research for scientists and researchers alongside textile and polymer engineers. Simulations of statistical data and regression equations of simplified mathematical models were obtained; they merge the user's need with the technological capabilities and programs offered by Microsoft Visual studio program.

A large amount of technical data from the effect of production process parameters could be obtained by using the designed process programme before moving to the production line. From the research that had been done, it is possible to conclude that the programmed application powerfully supports product development, design process control, quality assurance and product performance evaluation; it displays data on the screen or sends data to a file or other devices. The program's results help in achieving a balance between the enhanced properties and the fiber cost. After finishing the processes for modeled biodegradable fibers, the process conditions (Process-Input Data) selected depends upon the user needs. The goal of this thesis is the modelling of the production process of aliphatic-aromatic copolyester fibres and yarns used in the textile industry for tomorrow's environment. The AAC textiles could be used for different applications, as an alternative to commercial chemical fibres at reasonable cost, leaving no environmental footprint. Staple fibres, continuous fibres, stable yarns, continuous yarns and twisted yarns for different applications could be manufactured from fibre producers. Fabric made from such flat continuous filament yarns exhibits shine and is smooth with minimal surface friction.

\section{Acknowledgements}

The author is indebted to the Textiles Engineering Department/ Faculty of Mechanical and Electrical Engineering/Damascus University, Syria for the research support. The author is indebted to Dr. Alex Fotheringham in the extrusion lab/the School of Textiles and Design/HeriotWatt University, United kingdom for the greatly valued support.

\section{References}

[1] A. Steinbüchel, Biopolymers Vol. 10: General Aspects and Special Applications Vol. 10, Wiley-VCH, Germany, 2003.

[2] N. Tasnim, "Eco-friendly Manufacturing Process of Casein Fiber with It's Sustainable Features \& Comfortable Uses," American Journal of Environmental Engineering, 9: 2 (2019), 31-35

[3] R. Smith, Biodegradable Polymers for Industrial Applications, Woodhead Publishing Limited, England, 2005.

[4] H. R. T. A. B. Abdul Jabbar Muhammad Tausif, Muhammad Rehan Asghar Bhatti \& Ghulam Abbas, "Polylactic acid/lyocell fibre as an eco-friendly alternative to polyethylene terephthalate/cotton fibre blended yarns and knitted fabrics," The Journal of The Textile Institute, 111: 1 (2020), 129-138. 
[5] W. Holding, Biodegradable Polymer Supply Chains: Implications and Opportunities for Australian Agriculture, Rural Industries Research and Development Corporation, Australia 2004.

[6] Monsanto, "Biopolymers to Give Cotton Fibers SyntheticLike Qualities," Monsanto company, U.S.A, 2003.

[7] C. Bastioli, Handbook of Biodegradable Polymers, Rabra Technology, Shawbury, UK, 2005.

[8] G. K. Hoeschele, "Thermostabile Polyester-BlockCopolymere," US Patent 3954689 (1976).

[9] Y. Chen, L. Tan, L. Chen, Y. Yang, and X. Wang, "Study on Biodegradable Aromatic/Aliphatic Copolyester," Brazilian Journal of Chemical Engineering, 25: 2 (2008), 321-335.

[10] W. Xiao-Hui, S. Jun, C. Ying, F. Zhi-Feng, and S. Yan, "Study on Structure and Crystallinity of a New Biodegradable Aliphatic-Aromatic Copolyester," Petrochemical Research, 13: 4 (2011), 64-69.

[11] S. S. Park, S. H. Chae, and S. S. Im, "Transesterification and crystallization behavior of poly (butylene succinate)/poly (butylene terephthalate) block copolymers," Journal of Polymer Science, Part A: Polymer Chemistry 36: 1 (1998), 147-156.

[12] R. A. Hayes, "Aliphatic-aromatic copolyesters," US Patent 6485819 (2002).

[13] P. Pan and Y. Inoue, "Polymorphism and isomorphism in biodegradable polyesters," Progress in Polymer Science: 34 (2009), 605-640.

[14] H. C. Ki and O. O. Park, "Synthesis, characterization and biodegradability of the biodegradable aliphatic-aromatic random copolyesters," Polymer, 42 (2001), 1849-1861.

[15] Y. Tokiwa, T. Suzoki, and J. Appl, "Hydrolysis of copolyesters containing aromatic and aliphatic ester blocks by lipase," Journal of Applied Polymer Science, 26: 2 (1981), 441-448.

[16] H.-J. Jin, B.-Y. Lee, M.-N. Kim, and J.-S. Yoon, "Thermal and mechanical properties of mandelic acid-copolymerized poly (butylene succinate) and poly (ethylene adipate)," Journal of Polymer Science, Part B: Polymer Physics, 38 (2000), 15041511.

[17] "Standard guide for assessing the compostability of environmentally degradable plastics, D 6002-96," American Society for Testing and Materials, Washington, D.C. (1996).

[18] H. Sawada, "ISO standard activities in standardization of biodegradability of plastics-development of test methods and definitions," Polymer degradation and Stability, 59 (1998), 365-370.

[19] M. P. Pavlov, J. F. Mano, N. M. Neves, and R. L. Reis, "Fibres and 3D mesh scaffolds from Biodegradable starch based blends: production and characterization," Macromolecular bioscience 4 (2004), 776-784.

[20] Y. Chen, R. Wombacher, J. H. Wendorff, J. Visjager, P. Smith, and A. Greiner, "Design, Synthesis, and Properties of New Biodegradable Aromatic/Aliphatic Liquid Crystalline Copolyesters," Biomacromolecules, 4: 4 (2003), 974 -980.

[21] L. Han, G. Zhu, W. Zhang, and W. Chen, "Composition, Thermal Properties, and Biodegradability of a New Biodegradable Aliphatic/Aromatic Copolyester," Journal of applied polymer science, 113: 2 (2009), 1298-1306.

[22] L. Averous, "Biodegradable multiphase systems based on plasticized starch: a review," Journal of Macromolecular Science - Polymer Reviews, 44: 3 (2004), 231-274.

[23] P. Prowans, M. E. Fray, and J. Slonecki, "Biocompatibility studies of new multiblock poly (ester-ester) s composed of poly (butylene terephthalate) and dimerized fatty acid," Biomaterials, 23: 14 (2002), 2973-2978.

[24] M. Renke-Gluszko and M. E. Fray, "The effect of simulated body fluid on the mechanical properties of multiblock poly (aliphatic/aromatic-ester) copolymers," Biomaterials, 25: 21 (2004), 5191-5198.

[25] L. Fumin, W. A. Haile, M. E. Tincher, and W. S. Harris, "BioDegradable Copolyester Nonwoven Fabric," European Patent EP1330350 (2003).

[26] Author, "Biodegradable Aliphatic-Aromatic Copolyester for use in Nonwoven Webs," U.S. Patent 2008).

[27] Author, "Bio-degradable Copolyester Nonwoven Fabric," U.S. Patent 2002).

[28] M. Râpă, M. E. Popa, P. Cinelli, A. Lazzeri, R. Burnichi, A. Mitelut, and E. Grosu, "Biodegradable alternative to plastics for agriculture application," ACRomanian Biotechnological Letters, 16: 6 (2011), 59-64.

[29] Author, "Biodegradable Aliphatic-Aromatic Copolyesters, Methods of Manufacture, and Articles Thereof " U.S. Patent 03/24/2011).

[30] Eastman polymers for fibres, Eastman chemical company, USA, 2002

[31] R. S. Blackburn, Biodegradable and Sustainable Fibres, Woodhead Publishing, Cambridge, UK, 2005.

[32] M. Rolf-Joachim, K. Ilona, and D. Wolf-Dieter, "Biodegradation of polyesters containing aromatic constituents," Journal of biotechnology, 86: 2 (2001), 87-95.

[33] U. Witt, R.-J. Muller, and W.-D. Deckwer, "New biodegradable polyester-copolyesters from commodity chemicals with favorable use properties," Journal of Polymers and the Environment, 3: 4 (1995), 215-223.

[34] B. Younes, "Simple Rheological Analysis Method of Spinnable-Polymer Flow Properties Using MFI Tester," Indian Journal of Materials Science: 2015 (2015), 1-8.

[35] U. Witt, R.-J. Müller, and W.-D. Deckwer, "Studies on sequence distribution of aliphatic/aromatic copolyesters by high-resolution $\mathrm{C}$ nuclear magnetic resonance spectroscopy for evaluation of biodegradability," Makromol Chem Phys, 197 (1996), 1525-1535.

[36] S. Lim, J. Lee, S. Jang, S. Lee, K. Lee, H. Choi, and J. Chin, "Synthetic Aliphatic Biodegradable Poly (butylene succinate)/Clay Nanocomposite Foams with High Blowing Ratio and Their Physical Characteristics," Polymer Engineering and Science, 123 (2011), 1316-1325.

[37] R. H. Lochner and J. E. Mater, Design for Quality, Chapman and Hall, London 1990.

[38] J. C. Moreland, J. L. Sharp, and P. J. Brown, "Lab-Scale Fiber Spinning Experimental Design Cost Comparison," Journal of Engineered Fibers and Fabrics, 5: 1 (2010), 39-49. 
[39] S. S. N. Perera, "Viscoelastic Effect in the Non-Isothermal Melt Spinning Processes," Applied Mathematical Sciences, 3: 4 (2009), 177-186.

[40] G. X. Wang and E. F. Matthys, "Modelling of rapid solidification by meltspinning: effect of heat transfer in the cooling substrate," Materials Science and Engineering: A, 136 (1991), 85-97.

[41] A. Ziabicki, L. Jarecki, and A. Wasiak, "Dynamic modelling of melt spinning," Computational and Theoretical Polymer Science, 8: 1/2 (1998), 143-157.

[42] T. Kotze, Two Dimensional Modelling of PET Melt Spinning: The effects of heat transfer limitations on the quality of PET yarn produced during melt spinning, LAP LAMBERT Academic Publishing, 2010.

[43] W. He, S. Zhang, and X. Wang, "Mechanical Behavior of Irregular Fibers, Part I: Modeling the Tensile Behavior of Linear Elastic Fibers," Textile Research Journal, 71: 6 (2001), 556-560.

[44] D. Bingol, N. Tekin, and M. Alkan, "Brilliant Yellow dye adsorption onto sepiolite using a full factorial design," Applied Clay Science, 50: 3 (2010), 315-321.

[45] T. O. Hanci, I. A. Alaton, and G. Basar, "Multivariate analysis of anionic, cationic and nonionic textile surfactant degradation with the $\mathrm{H} 2 \mathrm{O} 2$ /UV-C process by using the capabilities of response surface methodology," Journal of Hazardous Materials, 185,: 1 (2011), 193-203.

[46] A. B. Engin, Ö. Özdemir, M. Turan, and A. Z. Turan, "Color removal from textile dyebath effluents in a zeolite fixed bed reactor: Determination of optimum process conditions using Taguchi method," Journal of Hazardous Materials, 159: 2-3 (2008), 348-353.

[47] I. Krucinska, "The influence of technological parameters on the filtration efficiency of electret needled non-woven fabrics," Article Journal of Electrostatics, 56: 2 (2002), 143153.

[48] W. P. Gardiner and G. Gettinby, Experimental Design Techniques in Statistical Practice, A practical Software-Based Approach, Horwood Publishing Limited, Chichester, England, 1998.

[49] B. Younes, S. C. Ward, R. M. Christie, and S. Vettese, "Textile applications of commercial photochromic dyes: part 7. A statistical investigation of the influence of photochromic dyes on the mechanical properties of thermoplastic fibres," The Journal of The Textile Institute, 110: 5 (2019), 780-790.

[50] J. G. Vlachogiannis and R. K. Roy, "Robust PID controllers by taguchi method" The TOM magazine, 17: 5 (2005), 456466.

[51] B. Younes, "A Statistical Investigation of the Influence of the Multi-Stage Hot-Drawing Process on the Mechanical Properties of Biodegradable Linear Aliphatic-Aromatic CoPolyester Fibers," Advances in Materials Science and Applications, 3: 4 (2014), 186-202.

[52] B. Younes, The Statistical Modelling of Production Processes of Biodegradable Aliphatic Aromatic Co-Polyester Fibres used in the Textile Industry, PhD Thesis, Heriot-Watt University, 2012.

[53] B. Younes, "Modelling of the blend ratio effect on the mechanical properties of the biofibres," The Journal of The Textile Institute 108: 5 (2017), 692-702.

[54] B. Younes, "Classification, characterization, and the production processes of biopolymers used in the textiles industry," The Journal of The Textile Institute, 108: 5 (2017), 674-682.

[55] X. Chen, Modelling and predicting textile behaviour, Woodhead Publishing Ltd, UK, 2010.

[56] G. Tanguchi, Introduction to Quality Engineering, Asian productivity organization, Tokyo, 1986.

[57] J. N. Cawse, Experimental Design for Combinatorial and High Throughput Materials Development, John Wiley and Sons, Inc, USA, 2003.

[58] STATGRAPHICS, "STATGRAPHICS Plus Version 5.1," USA (2001).

[59] H. Brody, Synthetic fibre materials, Longman group UK limited London, 1994.

[60] V. Capasso, Mathematical modelling for polymer processing, Springer-Verlag Berlin Heidelberg, New York, 2003.

[61] W. Callister, Materials Science and Engineering: An Introduction, John Wiley and Sons, New York, 1999.

[62] B. Younes, "Investigating the co-effect of twist and hot drawing processes on the bio-based yarns properties," The Journal of The Textile Institute, 111: 2 (2020), 202-213.

[63] J. v. Meerveld, M. Hutter, and G. W. M. Peters, "Continuum model for the simulation of fiber spinning, with quiescent and flow-induced crystallization," J. Non-Newtonian Fluid Mech, 150 (2008), 177-195.

[64] A. Ziabicki, Fundamental of Fibre Formation, John Wiley \&Sons, London, 1976. 